\title{
TRAP-5' stem-loop interaction increases the efficiency of transcription termination in the Bacillus subtilis trpEDCFBA operon leader region
}

\author{
ADAM P. MCGRAW, ${ }^{1,2}$ PHILIP C. BEVILACQUA, ${ }^{2}$ and PAUL BABITZKE ${ }^{1}$ \\ ${ }^{1}$ Department of Biochemistry and Molecular Biology, The Pennsylvania State University, University Park, Pennsylvania 16802, USA \\ ${ }^{2}$ Department of Chemistry, The Pennsylvania State University, University Park, Pennsylvania 16802, USA
}

\begin{abstract}
TRAP regulates expression of the Bacillus subtilis trpEDCFBA operon by a transcription attenuation mechanism in which tryptophan-activated TRAP binds to $11(\mathrm{G} / \mathrm{U}) \mathrm{AG}$ repeats in the nascent trp leader transcript. Bound TRAP blocks formation of an antiterminator structure and allows formation of an overlapping intrinsic terminator upstream of the trp operon structural genes. A $5^{\prime}$ stem-loop $\left(5^{\prime} \mathrm{SL}\right)$ structure located upstream of the triplet repeat region also interacts with TRAP. TRAP-5'SL RNA interaction participates in the transcription attenuation mechanism by preferentially increasing the affinity of TRAP for the nascent trp leader transcript during the early stages of transcription, when only a few triplet repeats have been synthesized. Footprinting assays indicated that the $5^{\prime}$ 'SL contacts TRAP through two discrete groups of single-stranded nucleotides that lie in the hairpin loop and in an internal loop. Filter binding and in vivo expression assays of 5'SL mutants established that G7, A8, and A9 from the internal loop, and A19 and G20 from the hairpin loop are critical for proper 5'SL function. These nucleotides are conserved among certain other 5'SL-containing organisms. Single-round transcription results indicated that the 5'SL increases the termination efficiency when transcription is fast; however, the influence of the $5^{\prime} \mathrm{SL}$ was lost when transcription was slowed by reducing the ribonucleoside triphosphate concentration. Since there is a limited amount of time for TRAP to bind to the nascent transcript and promote termination, our data suggest that the contribution of TRAP-5'SL interaction increases the rate of TRAP binding, which, in turn, increases the efficiency of transcription termination.
\end{abstract}

Keywords: TRAP; attenuation; RNA-binding protein; gene regulation; RNA structure

\section{INTRODUCTION}

The tryptophan biosynthesis pathway of Bacillus subtilis consists of seven enzymes, six of which are encoded within the $\operatorname{trpEDCFBA}$ operon (Gollnick et al. 2002, 2005). The $\operatorname{tr} p$ operon is part of a 12-gene aromatic amino acid supraoperon that also contains genes involved in general aromatic amino acid and histidine biosynthesis, including aroF-aroB-aroH upstream and hisH-tyrR-aroE downstream of the $\operatorname{trp}$ genes (Gollnick et al. 2002, 2005). Two promoters are used to transcribe the $\operatorname{trp}$ genes within the aro supraoperon. The first promoter is located at the beginning of the

\footnotetext{
Reprint requests to: Paul Babitzke, Department of Biochemistry and Molecular Biology, The Pennsylvania State University, University Park, PA 16802, USA; e-mail: pxb28@psu.edu; fax: 814-863-7024; Philip C. Bevilacqua, Department of Chemistry, The Pennsylvania State University, University Park, PA 16802, USA; e-mail: pcb@chem.psu.edu; fax: 814-863-8403.

Article published online ahead of print. Article and publication date are at http://www.rnajournal.org/cgi/doi/10.1261/rna.719507.
}

supraoperon (preceding aroF) and the second promoter is located upstream of the trp operon. Transcription initiation of the upstream promoter is regulated in response to aromatic amino acids by an unknown mechanism, while transcription initiation of the trp promoter is thought to be constitutive (Gollnick 1994; Gollnick et al. 2002, 2005).

Since tryptophan is a metabolically expensive amino acid to produce de novo, expression of the tryptophan biosynthesis enzymes is tightly regulated. The 11-subunit $\operatorname{trp}$ RNA-binding attenuation protein (TRAP) is a ring-shaped protein that controls expression of the trp operon by transcription attenuation (Gollnick et al. 1990; Babitzke and Yanofsky 1993; Babitzke 1997, 2004) and translation control (Merino et al. 1995; Du and Babitzke 1998) mechanisms (see below). TRAP also regulates expression of trpG (Yang et al. 1995; Du et al. 1997, Yakhnin et al. 2007), trpP (Sarsero et al. 2000a; Yakhnin et al. 2004), and $y c b K$ (Sarsero et al. 2000b; Yakhnin et al. 2006b), which encode a tryptophan biosynthesis enzyme, a tryptophan transporter, 
and a putative efflux protein, respectively. In the three latter cases, the TRAP-binding site overlaps the cognate Shine-Dalgarno (SD) sequence such that bound TRAP prevents ribosome binding.

When the intracellular concentration of tryptophan is high, 11 hydrophobic pockets that lie between adjacent subunits of TRAP each bind a single tryptophan molecule (Antson et al. 1995). Binding of tryptophan leads to a reordering of 11 cationic surface domains (KKR motifs), allowing these regions to interact with $\operatorname{trp}$ leader RNA (Antson et al. 1995, 1999; Yang et al. 1997; McElroy et al. 2006). The TRAP-binding site in the trp leader transcript contains $11(\mathrm{G} / \mathrm{U}) \mathrm{AG}$ triplet repeats separated by two or three nonconserved spacer nucleotides (Babitzke et al. 1995, 1996; Hopcroft et al. 2004). Since six of the triplet repeats lie within an antiterminator structure that promotes transcriptional readthrough, TRAP binding prevents formation of this structure, which allows formation of a mutually exclusive terminator hairpin (Fig. 1). Formation of this intrinsic terminator halts transcription before RNA polymerase (RNAP) reaches the trp operon structural genes. In the event that RNAP is able to transcribe past the terminator, TRAP binding provides additional repression of $\operatorname{trp} E$ translation by promoting formation of a hairpin that sequesters the $\operatorname{trp} E \mathrm{SD}$ sequence (Merino et al. 1995; Du and Babitzke 1998). The combined effect of these two regulatory mechanisms results in $>1000$-fold repression of $\operatorname{trp} E$ expression in vivo (Merino et al. 1995).

In addition to the antiterminator and terminator structures, a $5^{\prime}$ stem-loop $\left(5^{\prime} \mathrm{SL}\right)$ forms just upstream of the triplet repeat region within the trp leader transcript (Fig. 1). While this structure is not part of the well-characterized triplet repeat TRAP-binding site, previous results demonstrated that TRAP interacts with this RNA structure, although the sequence elements within the 5'SL responsible for this interaction were not established ( $\mathrm{Du}$ et al. 2000). Deletion of the $5^{\prime} \mathrm{SL}$ resulted in elevated expression of the trp operon and a reduced ability to regulate expression in response to tryptophan. This phenotype could be suppressed by overexpression of $m t r B$, the gene encoding TRAP, suggesting that the $5^{\prime} \mathrm{SL}$ functions by increasing the affinity of TRAP for $\operatorname{trp}$ leader RNA (Sudershana et al. 1999). Several point mutations in the $5^{\prime}$ SL were also found to interfere with TRAP-mediated regulation of the trp operon in both the presence and absence of exogenously added tryptophan; however, the effect of these mutations on TRAP binding was not examined (Sudershana et al. 1999). Finally, nuclease protection (footprinting) assays suggested that TRAP interaction with the 5'SL depended on the number of downstream repeats (Du et al. 2000).

To determine the mechanism of TRAP-5'SL interaction and how this interaction contributes to the attenuation mechanism, we characterized an extensive series of $\operatorname{tr} p$ leaders that differed in the $5^{\prime} \mathrm{SL}$ sequence and/or the number of downstream (G/U)AG repeats. Our studies show that TRAP binds to two distinct regions of the 5'SL, and that these interactions increase the affinity of TRAP for $\operatorname{trp}$ leader RNA during the initial stages of transcription when only a few triplet repeats have been synthesized by RNAP. The results of our studies suggest that TRAP-5'SL interaction increases the likelihood that TRAP will bind



FIGURE 1. Model of the Bacillus subtilis trpEDCFBA operon transcription attenuation mechanism. The native default conformation of the $\operatorname{trp}$ leader (top) under conditions of limiting tryptophan includes the $5^{\prime} \mathrm{SL}$ and a stable antiterminator hairpin, which allows transcriptional readthrough. Based on structure mapping experiments (Du et al. 2000), the RNA secondary structure for the $5^{\prime}$ SL has been modified slightly from the one predicted by Mfold (Zuker 2003). Under conditions of excess tryptophan (bottom), tryptophan-activated TRAP binds the triplet repeats (bold) in the nascent transcript and prevents formation of the antiterminator, favoring the formation of an intrinsic terminator hairpin that halts transcription at G140 or U141. An RNAP pause site identified in vitro at U107, the nucleotide just preceding the critical overlap between the antiterminator and terminator structures, may allow additional time for TRAP to bind (Yakhnin and Babitzke 2002; Yakhnin et al. 2006a). Since the terminator and antiterminator overlap by four nucleotides (boxed), the two structures are mutually exclusive. Residues corresponding to the terminator structure are shown in gray. (Reprinted, with permission from Gollnick et al. 2005; (2005 Annual Reviews, www.annualreviews.org.) 
quickly to the trp transcript and be available for interacting with the multipartite TRAP-binding site as soon as three or four triplet repeats are synthesized, thereby increasing the probability that TRAP will promote transcription termination by blocking formation of the antiterminator structure.

\section{RESULTS}

\section{The thermodynamic contribution of TRAP-5'SL interaction depends on the number of downstream $(\mathrm{G} / \mathrm{U}) \mathrm{AG}$ repeats}

The $5^{\prime} \mathrm{SL}$ is capable of forming in transcripts that initiate at both the aro and trp promoters. Mfold (Zuker 2003) predictions did not identify any structures capable of competing with the $5^{\prime} \mathrm{SL}$ in transcripts originating from either promoter. Previous studies established that the 5'SL participates in the B. subtilis trp operon attenuation mechanism (Sudershana et al. 1999) and that this structure does not function as an RNA polymerase pause signal (Yakhnin and Babitzke 2002). Instead, it was shown that the 5'SL contributes to TRAP binding by increasing the affinity of TRAP for trp leader RNA (Du et al. 2000). A series of RNAs analogous to $3^{\prime}$-truncated portions of the trp leader RNA were generated to determine the effect of the $5^{\prime} \mathrm{SL}$ on the affinity of TRAP-RNA interaction. These RNAs were designed to mimic a transcript emerging cotranscriptionally from RNAP, in the presence or absence of the $5^{\prime} \mathrm{SL}$. It is important to note that the antiterminator was not capable of forming in these RNAs, as the longest transcript only extended to position +91 (Fig. 1). Thus, the $5^{\prime} \mathrm{SL}$ was the only significant structure that was predicted to form in any of these transcripts. Gel shift and filter binding assays were used to measure the dissociation constants (Kd) of TRAP interaction with each transcript. The values determined by the two methods deviated from each other by less than twofold (data not shown). All Kd values reported herein were derived from filter binding. Both in the presence and absence of the 5'SL, the Kd values decreased as the number of triplet repeats increased (Fig. 2A). This finding is consistent with previous studies demonstrating that the affinity of TRAP-RNA interaction increases in a repeat-dependent manner (Babitzke et al. 1996; Elliott et al. 2001). Interestingly, the $5^{\prime}$ SL was found to contribute to the free energy of TRAP-RNA interaction when three to nine downstream repeats were present, but had little effect when the transcript contained 10 or 11 repeats (Fig. 2B). Extrapolation of surface plasmon resonance (SPR) association curves verified that all filterbinding reactions had reached equilibrium during the incubation period (data not shown), indicating that the experiments were not influenced by slow kinetics that result from low protein concentrations.

It was previously shown that TRAP protects doublestranded regions of the 5'SL from RNase $\mathrm{V}_{1}$ cleavage when
A

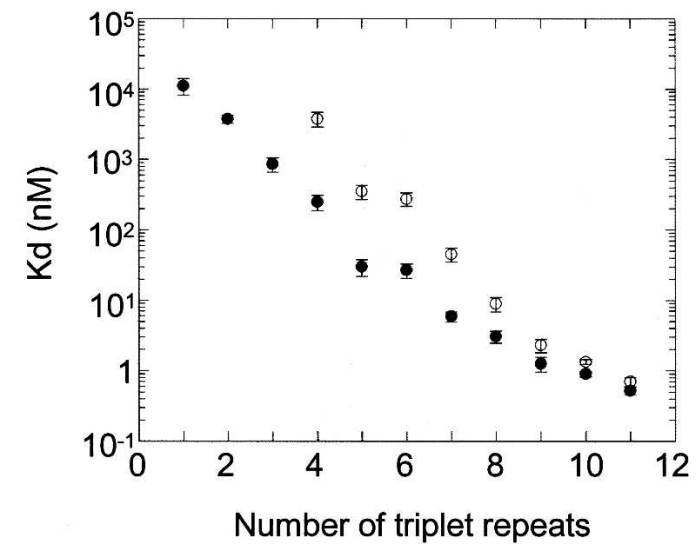

B

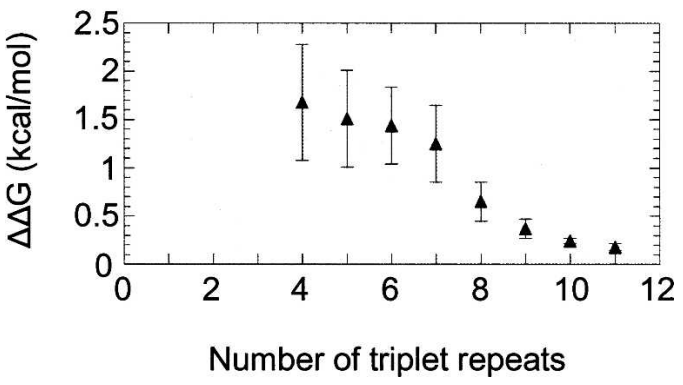

FIGURE 2. Energetic contribution of the $5^{\prime}$ SL to TRAP binding to transcripts containing various numbers of downstream triplet repeats. (A) Semi-logarithmic dependence of dissociation constants (nM) on the number of triplet repeats with $(-)$ and without $(\bigcirc)$ the $5^{\prime}$ SL. A transcript containing three triplet repeats without the 5'SL showed no appreciable binding at TRAP concentrations up to $20 \mu \mathrm{M}$. Values are the average of at least two independent experiments performed in duplicate with the standard deviation shown. (B) $\Delta \Delta \mathrm{G}$ values (kcal/ mol) describe the energetic penalty imposed on the interaction by deleting the 5'SL. Values are calculated from data in $A$ and plotted versus the number of downstream triplet repeats.

the transcript contains three, six, or nine downstream triplet repeats, but not when the transcript contains 0 or 11 triplet repeats ( $\mathrm{Du}$ et al. 2000). To expand upon this work, TRAP-RNA footprinting experiments using RNase $\mathrm{T}_{1}$ and $\mathrm{RNase} \mathrm{V}_{1}$ were conducted on transcripts containing the $5^{\prime} \mathrm{SL}$ and between two and 11 downstream repeats (Fig. 3A). As RNase $T_{1}$ cleaves $3^{\prime}$ to single-stranded $G$ residues and RNase $V_{1}$ cleaves double-stranded regions of RNA, these experiments probe the primary sequence as well as the secondary structure of the $5^{\prime} \mathrm{SL}$. The cleavage pattern was compared in the presence and absence of bound TRAP using TRAP concentrations that were at least 10-fold higher than the corresponding $\mathrm{Kd}$ value measured by filter binding. Bound TRAP protected several nucleotides in the $5^{\prime}$ SL from nucleolytic cleavage when the transcript contained nine or fewer triplet repeats, although protection was relatively weak for the transcript containing two repeats. Residues G7, G18, G20, and G31 were protected from RNase $\mathrm{T}_{1}$ cleavage by bound TRAP. TRAP also 
A
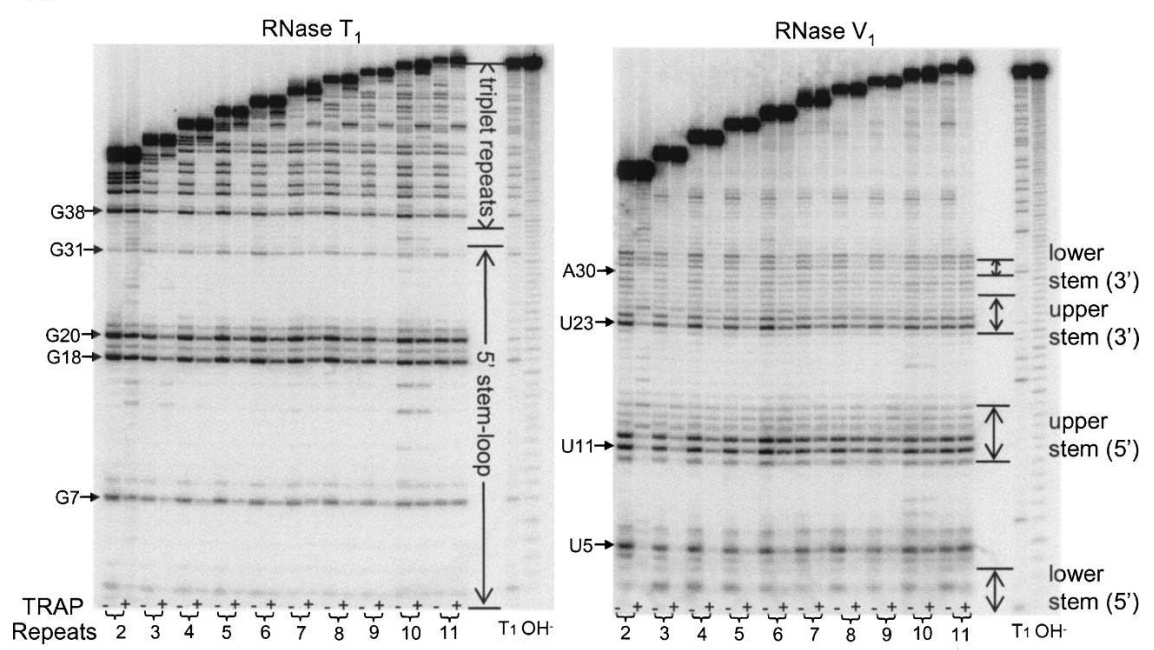

B

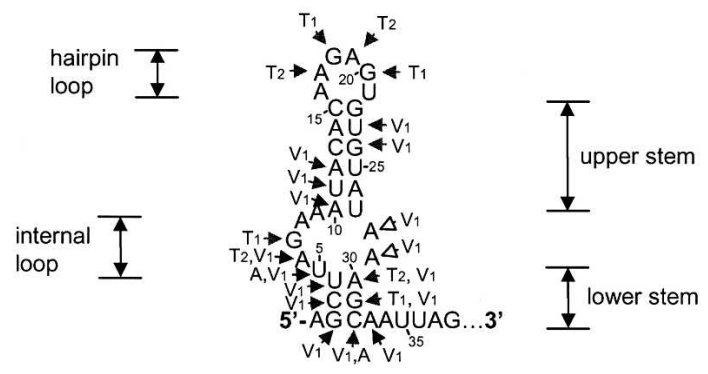

FIGURE 3. TRAP-5'SL RNA footprint. (A) The single-strand G-specific RNase $\mathrm{T}_{1}$ and double-strand-specific RNase $\mathrm{V}_{1}$ digestion patterns of transcripts containing the $5^{\prime} \mathrm{SL}$ and between two and 11 triplet repeats (left to right), with (+) and without (-) TRAP. Base hydrolysis $\left(\mathrm{OH}^{-}\right)$and denaturing RNase $\mathrm{T}_{1}$ digestion $\left(\mathrm{T}_{1}\right)$ ladders are also shown. The region of the RNase $\mathrm{T}_{1}$ gel corresponding to the $5^{\prime} \mathrm{SL}$ and triplet repeat region are marked to the left of the $T_{1}$ and hydrolysis ladders. Nucleotides involved in secondary structure formation are marked on the right of the RNase $\mathrm{V}_{1}$ gel. Prominent cleavage products are marked to the left of each gel. Note that RNase $\mathrm{V}_{1}$ did not cleave all double-stranded nucleotides, and it cannot be stated conclusively that these nucleotides were not protected by bound TRAP. (B) The composite TRAP-dependent protection pattern of the $5^{\prime} \mathrm{SL}$ with a transcript containing eight downstream triplet repeats. Black arrows indicate the annotated nucleotides were strongly protected, nucleotides with gray arrows were moderately protected, and nucleotides with open arrows were weakly protected. The cleaving nucleases are indicated adjacent to the arrows. Cleavage results with single-strand-specific RNase $\mathrm{T}_{2}$ and RNase A (gels not shown) are superimposed on the secondary structure.

protected nucleotides in the upper and lower stems of the $5^{\prime} \mathrm{SL}$ from cleavage by RNase $\mathrm{V}_{1}$. However, TRAP-mediated protection of these nucleotides was greatly diminished with the transcripts containing 10 or 11 downstream repeats. Importantly, protection of the triplet repeat region from RNase $T_{1}$ confirmed that TRAP bound to each of these RNAs. For example, nucleotide G38, which lies in the first triplet repeat, was protected from RNase $T_{1}$ cleavage in all of the transcripts that were tested. The finding that TRAP did not protect the $5^{\prime} \mathrm{SL}$ from RNase cleavage in the presence of 10 or 11 repeats is consistent with the filter binding data (Fig. 2) showing that the 5 'SL did not contribute to the affinity of TRAP-trp leader RNA interaction when the transcript contained 10 or 11 downstream repeats.
The RNase $T_{1}$ and $V_{1}$ footprinting results suggested that several discrete regions in the $5^{\prime}$ SL could be important in contacting TRAP. Additional experiments using RNase $\mathrm{T}_{2}$ (cleaves preferentially after single-stranded A residues) and RNase A (cleaves after singlestranded pyrimidines) were conducted to further characterize these regions. A transcript with the $5^{\prime}$ SL and eight downstream repeats was selected for these experiments, since the 5 'SL was protected in this transcript while still maintaining high affinity (Figs. 2A, 3). The protection pattern observed with all four nucleases is depicted in Figure 3B. Most of the $5^{\prime} \mathrm{SL}$ structure was protected by bound TRAP. The regions most strongly protected from the single-strand-specific nucleases include the hairpin loop, the $5^{\prime}$ side of the internal loop, and the lower stem. The cleavage pattern observed with the double-strand-specific RNase $V_{1}$ revealed protection of both the upper and lower stems. The finding that the lower stem was accessible to single-strand-specific nucleases indicates that the structure of this component of the $5^{\prime} \mathrm{SL}$ is dynamic. In addition, while Figures 1 and 3B show U5 and A29 as unpaired, the finding that both residues are also cleaved weakly by RNase V1 suggests that they are capable of pairing with one another some of the time.

\section{Point mutations in the $5^{\prime} \mathrm{SL}$ that interfere with TRAP interaction lead to elevated trp operon expression}

While the 11 verified triplet repeats within the $\operatorname{trp}$ leader are either GAG or UAG, AAG and CAG repeats have been shown to function in TRAP binding to $\operatorname{trp} G$, $\operatorname{trp} P$, and/or $y c b K$ transcripts (Du et al. 1997; Yakhnin et al. 2004, 2006b). Examination of the 5 'SL sequence revealed that there were three potential triplet repeats: -1 (AAG from A29 to G31), -2a (GAG from G18 to G20), -2b (AAG from A16 to G18), and -3 (UAG from U5 to G7) (Fig. 4). Since repeats $-2 \mathrm{a}$ and $-2 \mathrm{~b}$ overlap, we considered them as alternatives for one triplet repeat. One of the possible modes of TRAP-5'SL interaction could involve binding of one or more of these upstream triplet sequences with KKR motifs in TRAP. Alternatively, singlestranded nucleotides within the hairpin loop and/or internal loop of the 5'SL could interact with regions of TRAP other than the KKR motifs. To differentiate between these 


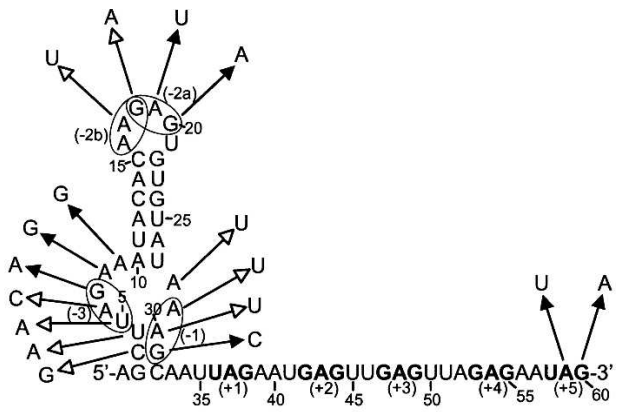

\begin{tabular}{|c|c|c|c|c|c|c|c|}
\hline \multirow{2}{*}{$\begin{array}{l}\text { Relevant } \\
\text { genotype }\end{array}$} & \multirow[b]{2}{*}{ Class of mutation } & \multirow[b]{2}{*}{$\mathrm{Kd}(\mathrm{nM})$} & \multirow{2}{*}{$\frac{\mathrm{Kd} \text { mut }}{\mathrm{Kd} \mathrm{WT}}$} & \multicolumn{2}{|c|}{$\beta$-gal activity } & \multirow{2}{*}{$\begin{array}{c}\text { B-gal ratio } \\
(- \text { Trp)/(+Trp) }\end{array}$} & \multirow{2}{*}{$\frac{+ \text { Trp mut }}{+\operatorname{Trp} \text { WT }}$} \\
\hline & & & & $-\overline{T r p}$ & $+\operatorname{Trp}$ & & \\
\hline WT & none & $6.9 \pm 1$ & 1 & $44 \pm 4$ & $<0.5$ & $>88$ & 1 \\
\hline$\triangle 5^{\prime} S L$ & 5'SL deletion & $110 \pm 20$ & 16 & $270 \pm 30$ & $10 \pm 3$ & 27 & $>20$ \\
\hline$\Delta m t r B$ & TRAP deletion & N.A. & N.A. & $290 \pm 40$ & $270 \pm 20$ & 1 & $>530$ \\
\hline$\Delta 5 ' S L \Delta m t r B$ & 5 'SL, TRAP deletions & N.A. & N.A. & $940 \pm 10$ & $960 \pm 100$ & 1 & $>1900$ \\
\hline C3G & 5'SL lower stem & $4.6 \pm 0.8$ & 0.7 & & & & \\
\hline U4A & 5'SL lower stem & $3.7 \pm 1$ & 0.5 & & & & \\
\hline U5A & 5'SL lower stem & $5.1 \pm 1$ & 0.7 & & & & \\
\hline $\mathrm{A} 6 \mathrm{C}$ & 5'SL internal loop & $11 \pm 2$ & 1.6 & & & & \\
\hline G7A & 5'SL internal loop & $42 \pm 5$ & 6.1 & $320 \pm 70$ & $5.7 \pm 2$ & 56 & $>11$ \\
\hline A8G & 5'SL internal loop & $23 \pm 7$ & 3.3 & $210 \pm 40$ & $<0.5$ & $>420$ & 1 \\
\hline A9G & 5 'SL internal loop & $52 \pm 10$ & 7.5 & $250 \pm 20$ & $2.0 \pm 0.8$ & 125 & $>4$ \\
\hline A17U & 5'SL hairpin loop & $13 \pm 4$ & 1.9 & $280 \pm 50$ & $<0.5$ & $>560$ & 1 \\
\hline G18A & 5'SL hairpin loop & $8.9 \pm 3$ & 1.3 & & & & \\
\hline A19U & 5'SL hairpin loop & $30 \pm 7$ & 4.3 & $240 \pm 70$ & $2.7 \pm 0.5$ & 89 & $>5$ \\
\hline G20A & 5'SL hairpin loop & $21 \pm 4$ & 3.0 & $330 \pm 50$ & $5.6 \pm 2$ & 59 & $>11$ \\
\hline $\mathrm{A} 28 \mathrm{U}$ & $5^{\prime} S L$ internal loop & $15 \pm 5$ & 2.2 & & & & \\
\hline A29U & 5'SL internal loop & $12 \pm 4$ & 1.7 & & & & \\
\hline $\mathrm{A} 30 \mathrm{U}$ & 5'SL lower stem & $9.1 \pm 2$ & 1.3 & $95 \pm 20$ & $<0.5$ & $>190$ & 1 \\
\hline G31C & 5'SL lower stem & $23 \pm 7$ & 3.3 & & & & \\
\hline C3G:G31C & 5'SL compensatory & $7.0 \pm 1$ & 1.0 & & & & \\
\hline U4A:A30U & 5'SL compensatory & $11 \pm 4$ & 1.6 & & & & \\
\hline U5A:A29U & 5'SL compensatory & $8.0 \pm 2$ & 1.2 & & & & \\
\hline A17U:A19U & 5'SL hairpin loop & $14 \pm 4$ & 2.0 & & & & \\
\hline G18A:G20A & 5'SL hairpin loop & $28 \pm 5$ & 4.1 & & & & \\
\hline A59U & $5^{\text {th }}(G / U) A G$ repeat & $50 \pm 8$ & 7.2 & & & & \\
\hline G60A & $5^{\text {th }}(G / U) A G$ repeat & $31 \pm 5$ & 4.5 & & & & \\
\hline
\end{tabular}

FIGURE 4. In vitro and in vivo characterization of $5^{\prime}$ SL mutants. The location of the various mutations that were investigated is superimposed on the $5^{\prime}$ SL structure (top). Open arrows indicate the mutation had no significant effect. Mutations with solid arrows resulted in a decrease in TRAP-binding affinity in vitro and/or elevated $\operatorname{trp} E^{\prime}-l a c Z$ expression in vivo. The putative triplet repeats within the $5^{\prime} \mathrm{SL}$ are circled and numbered from -1 to -3 . Known triplet repeats are numbered from +1 to +5 and are shown in bold. Tabulated data (bottom) for each of the $\operatorname{trp}$ leader and/or $m \operatorname{trB}$ mutants investigated are the average of at least three independent experiments \pm standard deviation. Mutations with significant effects are shown in bold. Kd values $(\mathrm{nM})$ pertain to transcripts with only five downstream triplet repeats. $\beta$-galactosidase ( $\beta$-gal) activity expressed from the $\operatorname{trp} E^{\prime}-$ 'lac $Z$ translational fusions is reported in Miller units (Miller 1972). (N.A.) Not applicable.

two models, a series of RNAs were generated that contained various point mutations in the $5^{\prime} \mathrm{SL}$ and the $\mathrm{Kd}$ for each RNA was determined by filter binding. As shown in Figure 2 , the difference in affinity between wild-type transcripts with five repeats with or without the $5^{\prime} \mathrm{SL}$ was large, but both RNAs still exhibit moderate affinity. Thus, mutations were introduced into a transcript that contained five downstream repeats to maximize the effect of a destabilizing mutation. Mutant transcripts were folded using Mfold (Zuker 2003) to assure that alternative structures were not predicted to form. In general, purines were substituted with purines to maintain similar shapes unless the fold was altered.
Altering the $5^{\prime}$ side of the internal loop (G7, A8, and A9) and the $3^{\prime}$ side of the hairpin loop (A19 and G20) led to a three- to eightfold decrease in affinity (Fig. 4), suggesting that nucleotides in these regions are important for TRAPtrp leader RNA interaction. These regions also exhibited significant protection from RNase cleavage in the presence of TRAP (Fig. 3). Substitution of an A residue for G31, which lies in the lower stem of the $5^{\prime} \mathrm{SL}$, also led to decreased affinity; however, this effect could be due to alteration of the $5^{\prime} \mathrm{SL}$ structure rather than disruption of a specific contact that TRAP makes with this nucleotide. Consistent with this interpretation, the C3G:G31C compensatory double mutant, which restored base pairing, exhibited wild-type binding affinity (Fig. 4). The finding that the C3G mutation had no effect on the TRAP-5'SL interaction might be due to the relatively stable nature of G-G mismatches in a duplex (Morse and Draper 1995; Bevilacqua and Bevilacqua 1998; Kierzek et al. 1999). C-C mismatches, as would be formed in the G31C single mutant transcript, are among the most destabilizing (Morse and Draper 1995; Bevilacqua and Bevilacqua 1998; Kierzek et al. 1999; Salehi-Ashtiani et al. 2006), and therefore, would be the most likely to result in decreased affinity if the corresponding base pair was functionally important. Altering C3, U4, U5, A6, A17, G18, A28, A29, or A30 did not significantly affect the measured Kd value (Fig. 4), suggesting that these nucleotides are not critical for TRAP-5'SL interaction. Finally, the decrease in affinity caused by mutations in the fifth triplet repeat (A59U and G60A) was similar to what was observed when either the $5^{\prime}$ side of the internal loop or $3^{\prime}$ side of the hairpin loop was altered (Fig. 4) (see Discussion).

As mentioned earlier, studies have shown that while any nucleotide can occupy the first position of a triplet repeat ( $G$ or $U$ is preferred), the second and third positions must be A and G, respectively (Babitzke et al. 1995). Since the A30U, G18A, and A6C mutations have no effect on affinity, the $-1,-2 b$, and -3 motifs likely do not act as triplet repeats. It is possible that the $-2 \mathrm{a}$ motif acts as a triplet repeat, since the A19U and G20A mutations both lead to decreased TRAP affinity; however, the fact that the remaining (G/U/A)AG 
sequences within the $5^{\prime}$ SL have been excluded makes the possibility of the $-2 \mathrm{a}$ motif acting as a sole triplet repeat seem less likely. Instead, the $5^{\prime}$ SL probably contacts TRAP through a repeat-independent mechanism via singlestranded nucleotides in the $5^{\prime}$ side of the internal loop and the $3^{\prime}$ side of the hairpin loop. A third potential point of contact, the $3^{\prime}$ side of the internal loop, does not appear to make energetically important contacts with TRAP.

Previous studies showed that a number of mutations altering the $5^{\prime} \mathrm{SL}$ sequence and/or structure led to elevated expression in vivo (Sudershana et al. 1999). To further characterize important $5^{\prime}$ SL nucleotides, particularly in the single-stranded regions of this structure, $\operatorname{trp} E^{\prime}-{ }^{\prime}$ lac $Z$ translational fusions with various $5^{\prime} \mathrm{SL}$ mutations were integrated into the amyE locus of the B. subtilis chromosome. Mutations chosen for this analysis were based on our in vitro characterization. $\beta$-galactosidase activity derived from these fusions was measured both in the absence and presence of added tryptophan in the growth medium. Since TRAP only binds trp leader RNA tightly when tryptophan is in excess, expression values in the presence of added tryptophan were the most useful for characterizing the TRAP-5'SL interaction (Fig. 4). Deletion of the gene encoding TRAP ( $m$ trB) abolished all tryptophan-dependent regulation of the $\operatorname{tr} p E^{\prime}-$ 'lacZ fusion. As previously observed (Sudershana et al. 1999), deletion of the $5^{\prime}$ SL had the largest effect of the $\operatorname{trp}$ leader mutants investigated, exhibiting both increased $\operatorname{trp} E^{\prime}-{ }^{\prime} l a c Z$ fusion expression in the presence of added tryptophan and decreased regulation as compared with wild-type values. In agreement with the in vitro results, increased expression was observed with the G7A, A9G, A19U, and G20A mutant fusions when grown in the presence of excess tryptophan. Likewise, no measurable effect on expression was observed with the A17U and $\mathrm{A} 30 \mathrm{U}$ mutations, as would be predicted on the basis of their $\mathrm{Kd}$ values. The one exception for in vitro-in vivo correlation was A8G. Despite manifesting a modest 3.3-fold binding defect in vitro, no detectable change in expression was observed with this mutation when cells were grown in the presence of tryptophan. It is worth noting that because expression of the mutants with no effect in the presence of added tryptophan (A8G, A17U, and A30U) and the wild-type 5'SL are below detectable levels, it cannot be firmly concluded that these mutations have no effect on expression; however, any such effect would likely be small.

While the effect of the $5^{\prime} \mathrm{SL}$ mutations on expression in the presence of exogenously added tryptophan generally correlated with the effect on binding in vitro, all of the 5'SL mutations resulted in a two- to sixfold increase in $\operatorname{trp} E^{\prime}-{ }^{\prime} l a c Z$ expression in the absence of added tryptophan (Fig. 4). Furthermore, expression levels without added tryptophan in the $5^{\prime} \mathrm{SL}$ deletion strain $\left(\Delta 5^{\prime} \mathrm{SL}\right)$ were virtually identical to that of the TRAP null strain $(\Delta m t r B)$. It is not clear why several 5'SL mutations result in elevated expression under tryptophan-limiting conditions but not in the presence of excess tryptophan. Perhaps even slight perturbations of the 5'SL negatively influence TRAP binding at tryptophan concentrations in which TRAP is only partially activated.

The distance between the 5'SL and the first triplet repeat is only 3 nucleotides (nt). To determine whether this short distance is critical for 5 'SL function, 5, 7, or $10 \mathrm{~A}$ residues were inserted between positions +32 and +33 of the $\operatorname{trp}$ leader (Fig. 1). The effects of these insertions were examined as integrated $\operatorname{trp} E^{\prime}-{ }^{\prime} l a c Z$ translational fusions. These inserted A residues were predicted to be single-stranded and to not influence the structure of the $5^{\prime} \mathrm{SL}$ or the antiterminator structure. In all three cases, expression was increased about twofold, both in the absence and presence of added tryptophan (data not shown). The finding that lengthening the distance between the $5^{\prime} \mathrm{SL}$ and the first triplet repeat from 3 to $13 \mathrm{nt}$ had only a slight affect on expression of the trp operon indicates that the 3-nt spacing is not critical for $5^{\prime} \mathrm{SL}$ function, providing further support that interactions with the $5^{\prime} \mathrm{SL}$ are not triplet repeat-like.

\section{The $5^{\prime} \mathrm{SL}$ is evolutionarily conserved}

A BLAST (Altschul et al. 1990) search identified 14 organisms containing a likely TRAP binding site in the leader region of the $\operatorname{trp}$ operon. Eleven of these leaders contained a predicted 5'SL (Fig. 5), which fell into one of three phylogenetic groups. Group 1 organisms have thermodynamically weak $5^{\prime}$ SL structures that contain a relatively large number (four to five) of putative triplet repeats with near-optimal spacing (2 nt) (Babitzke et al. 1995, 1996; Baumann et al. 1997), suggesting that these sequences are an extension of the triplet repeat region of the TRAPbinding site rather than a $5^{\prime} \mathrm{SL}$ per se. Groups 2 and $35^{\prime} \mathrm{SL}$ structures are more stable than those from Group 1 and contain a short lower stem, an asymmetric internal loop, and a longer, more stable upper stem. Group 2 organisms are thermophilic, as is reflected in the high $\mathrm{G}+\mathrm{C}$ content of their 5'SL structures. Group 3 organisms, which include $B$. subtilis, have purine-rich internal loops and hairpin loops. Interestingly, the only single-stranded 5'SL nucleotides completely conserved in sequence and positioning across Group 3 organisms (G7, A8, A9, A19, and G20) are the ones we have shown to be important for TRAP binding in $B$. subtilis. These nucleotides are not conserved in the Group 2 organisms, which have pyrimidine-rich single-stranded regions, or Group 1 organisms, which are missing a GAAcontaining $5^{\prime}$-side of the internal loop.

Caldicellulosiruptor saccharolyticus, one of the three organisms identified that did not have a $5^{\prime} \mathrm{SL}$, appears to utilize a translation control mechanism in which the TRAPbinding site overlaps the trpE SD sequence and start codon, instead of a transcription attenuation mechanism (data not shown). This regulatory strategy is used to inhibit translation initiation of other tryptophan metabolism genes in B. subtilis (Du et al. 1997; Yakhnin et al. 2004, 2006b, 2007). Escherichia coli and Salmonella typhimurium use a trp repressor 


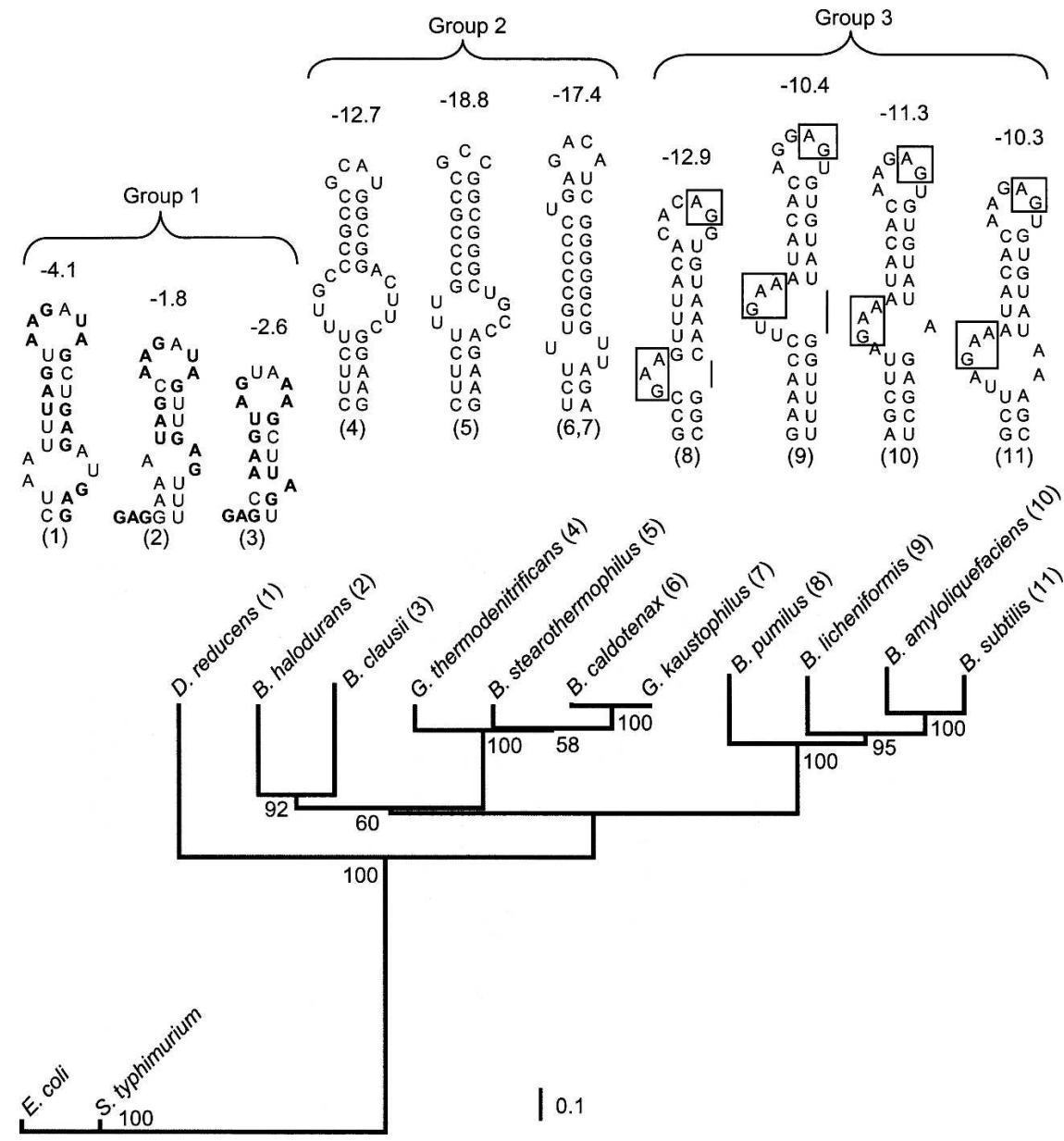

FIGURE 5. Phylogenetic comparison of the trp operon in 5 'SL-containing organisms. The phylogenetic tree was constructed from alignments of the trp structural genes and therefore reflects the evolution of the trp operon rather than the entire genome (Gutierrez-Preciado et al. 2007). Bootstrapping values (\%) are listed adjacent to each node. The vertical scale bar is in units of substitutions/position. Numbers adjacent to an organism's name correspond to the predicted $5^{\prime} \mathrm{SL}$ structure and free energy value $(\mathrm{kcal} / \mathrm{mol})$ at $37^{\circ} \mathrm{C}$ shown above. Each $5^{\prime} \mathrm{SL}$ falls into one of three catagories: thermodynamically weak structures with a high concentration of internal triplet repeats (Group 1; repeats shown in bold), G+C rich structures with pyrimidinerich loops and bulges (Group 2), and structures with purine-rich loops and bulges (Group 3). Nucleotides in the B. subtilis $5^{\prime}$ SL that our studies indicate are important in TRAP-trp leader RNA interaction are boxed (also shown in other Group 3 structures). The 5'SL structure shown for B. halodurans is slightly different from the one previously predicted (Szigeti et al. 2004). The structure shown here has a near equal free energy to that in Szigeti et al. (2004), but yields a $\operatorname{trp}$ leader more structurally reminiscent of the remaining organisms. Note that many organisms contain several single-stranded nucleotides upstream of the $5^{\prime} \mathrm{SL}$ (not shown in all cases).

protein to regulate transcription initiation and a leader peptide/stalled ribosome attenuation mechanism to regulate expression of their trp operons (Yanofsky and Crawford 1987) and are included to show the evolutionary distance between Gram-positive and Gram-negative bacteria (Fig. 5).

\section{The $5^{\prime} \mathrm{SL}$ increases the termination efficiency in the trp leader region at fast transcription rates}

Single-round in vitro transcription experiments were performed at varying ribonucleoside triphosphate (NTP) con- centrations to further characterize how the $5^{\prime}$ SL affects the rate of TRAP binding, and therefore the efficiency of transcription termination. It was previously shown that decreasing the rate of transcription by decreasing the NTP concentration increased TRAP's ability to promote transcription termination (Barbolina et al. 2007). Thus, we postulated that slowing the rate of transcription by decreasing the NTP concentration would allow more time for TRAP to bind to the nascent $\operatorname{trp}$ leader transcript, thereby negating the influence of the $5^{\prime}$ SL. At faster transcription rates (high NTP concentrations), however, TRAP would have less time to bind the transcript and the contribution from the 5 SL would become increasingly important.

To test this hypothesis, the termination efficiencies of elongation complexes initiated on templates containing G7A, G20A, or the $5^{\prime}$ SL deletion $\left(\Delta 5^{\prime} \mathrm{SL}\right)$ were compared with the wild-type template. These mutant constructs were chosen for analysis because they exhibited the largest effects on TRAP affinity and on in vivo expression (Fig. 4). The termination efficiency of the $\Delta 5^{\prime}$ SL template was reduced threefold relative to the wild-type template at the highest NTP concentration investigated (Fig. 6). This difference in termination efficiency was reduced as the NTP concentration was reduced. Moreover, the termination efficiencies of the wild-type and $\Delta 5^{\prime}$ SL templates were essentially identical at the lowest NTP concentrations, indicating that transcription was sufficiently slow that TRAP had time to bind to the nascent transcript without assistance from the $5^{\prime} \mathrm{SL}$. Templates carrying the G7A or G20A mutation had an intermediate effect at high NTP concentrations, but again showed no effect at low NTP concentrations (Fig. 6B). Due to changes in termination kinetics (McDowell et al. 1994), the termination efficiency at high or low NTP concentrations without TRAP varied by about twofold (data not shown). This effect occurred equally with all templates, and therefore did not affect comparisons between templates at a given NTP concentration.

\section{DISCUSSION}

The importance of RNA secondary structure in regulating gene expression is well-known (Yanofsky 2000; Merino and 
A
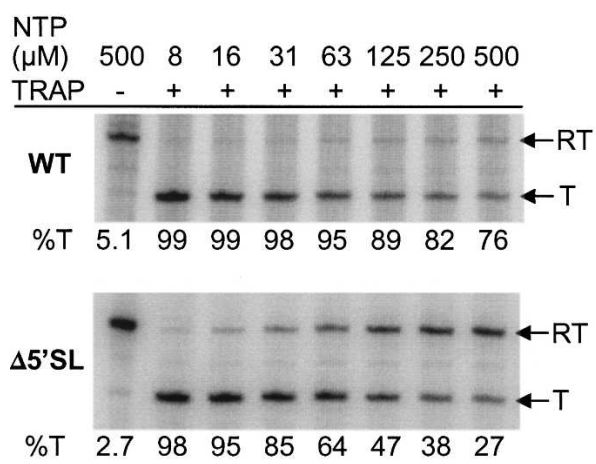

B

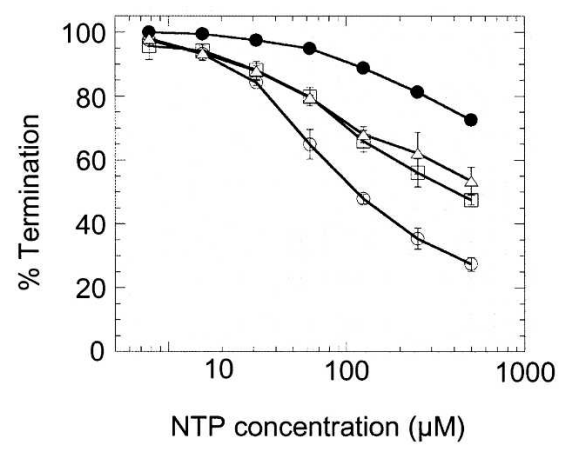

FIGURE 6. The effect of transcription rate and the $5^{\prime} \mathrm{SL}$ on termination efficiency. $(A)$ In vitro transcription assays are shown for wildtype and $\Delta 5^{\prime}$ SL templates at varying NTP concentrations. The key showing NTP and TRAP concentrations pertains to both gels. Positions of readthrough (RT) and terminated (T) transcripts are shown. Percent termination is reported beneath each lane. $(B)$ The percent termination observed with wild-type $(\bullet), \Delta 5^{\prime}$ SL $(\bigcirc)$, G7A $(\square)$, and G20A $(\triangle)$ templates as a function of NTP concentration. Error bars are derived from the standard deviation of three independent experiments.

Yanofsky 2005). The experiments presented here have shown that in addition to the antiterminator and terminator hairpins, the $5^{\prime} \mathrm{SL}$ is important for proper transcription attenuation control of the B. subtilis trp operon. Since the first terminator for transcripts originating from the upstream aroF promoter lies within trp leader RNA, it is apparent that expression from this promoter is controlled by the TRAP-dependent attenuation and translation control mechanisms; however, the relative contribution of the aroF and trp promoters to trp operon expression is not known. Furthermore, as the $5^{\prime} \mathrm{SL}$ is predicted to form in transcripts originating from both promoters, it is likely that this structure participates in attenuation of both transcripts.

The $5^{\prime} \mathrm{SL}$ increases the affinity of TRAP-trp leader RNA interaction with transcripts containing three to nine downstream repeats, but has no effect when 10 or 11 downstream repeats are present (Fig. 2). Single-stranded nucleotides in the $3^{\prime}$ side of the hairpin loop and the $5^{\prime}$ side of the internal loop are the most critical for TRAP-5'SL interaction (Fig. 4). These nucleotides are conserved in certain other Bacillus species (Fig. 5), suggesting that at least some of the organisms containing a $\operatorname{trp}$ leader $5^{\prime} \mathrm{SL}$ utilize this structure in the same fashion as in B. subtilis. Single-round in vitro transcription experiments suggest that the contribution of the $5^{\prime}$ SL to TRAP binding is manifested kinetically as an increase in the rate of TRAP binding, resulting in an increase in termination efficiency (Fig. 6).

\section{TRAP-5'SL interaction}

Footprinting and mutant studies show that the $5^{\prime}$ side of the internal loop and the $3^{\prime}$ side of the hairpin loop are the most important single-stranded regions for TRAP- $5^{\prime} \mathrm{SL}$ interaction (Figs. 3, 4). While additional 5'SL nucleotides are probably important to maintain the structure of this hairpin, G7, A8, A9, A19, and G20 are the nucleotides most likely to form direct contacts with TRAP. Consistent with this interpretation, structure prediction showed no expected structural changes for these mutations. Mutations in each of these positions reduced the transcript's affinity for TRAP, and with the exception of A8G, each of these mutant leaders led to elevated in vivo expression in the presence of added tryptophan (Fig. 4). These nucleotides are the only residues completely conserved across the Group 3 organisms (Fig. 5), strengthening the argument that they play an important role in TRAP- $5^{\prime}$ SL interaction for B. subtilis and closely related species. Since the A30U, G18A, and A6C mutations have no effect on affinity, it is unlikely that the $(\mathrm{G} / \mathrm{U} / \mathrm{A}) \mathrm{AG}$ sequences within the $5^{\prime} \mathrm{SL}$ interact with TRAP's KKR motifs, as is the case for the downstream triplet repeats; however, the -2a motif has not yet been experimentally excluded. Note that the A17U and A30U mutations also did not affect in vivo expression in the presence of added tryptophan. The most plausible model is one where single-stranded nucleotides in the loop and bulge of the 5'SL contact specific regions of the protein outside of the KKR motifs. Since no enhancements in nucleolytic cleavage were observed in the presence of bound TRAP (Fig. 3), it is unlikely that the 5' SL undergoes a structural rearrangement upon binding.

An interesting result from the footprinting experiments is that cleavage of residues A8, A9, A28, and A29 by RNase $\mathrm{T}_{2}$ was not observed, even though these nucleotides are predicted to be single stranded (Fig. 3B). Because the single-strand-specific RNase $\mathrm{T}_{2}$ did not cleave at these positions, combined with the finding that the doublestrand-specific RNase $V_{1}$ cleaved several residues in the internal loop, it is possible that the internal loop is structured. The UAA/GAN internal loop motif has been identified in numerous RNAs, where it contains a noncanonical G-A base pair and a cross-strand stacking of the three A residues (Lee et al. 2006). It is possible that U27, 
A28, A29, and G7, A8, and A9 form this (or a similar) structure that prevents RNase $\mathrm{T}_{2}$ cleavage. This motif creates a bend between the two helices of up to $60^{\circ}$ (Lee et al. 2006), which could be helpful in having an otherwise linear RNA secondary structure bind a toroid-shaped protein.

In most cases each triplet repeat contributes favorably to TRAP-RNA interaction. This is reflected in the largely linear dependence of $\log \mathrm{Kd}$ on the number of triplet repeats (Fig. 2A). However, the addition of the sixth triplet repeat has no effect on affinity (Fig. 2A). The lack of an energetic contribution by this particular repeat may be due to the two $G$ residues separating the fifth and sixth triplet repeats. RNase $T_{1}$ cleavage of these nucleotides is enhanced in the presence of TRAP (Fig. 3). The fact that these nucleotides are more accessible to RNase $T_{1}$ when bound to TRAP suggests that they buckle outward upon binding, reflecting the unfavorable nature of their positioning. The destabilizing effect associated with this suboptimal spacer (Babitzke et al. 1996) may negate the energetic contribution imparted by an additional triplet repeat; however, these $\mathrm{G}$ residues are vital for stabilizing the base of the antiterminator, which sequesters the four nucleotides that overlap with the terminator hairpin (Fig. 1).

Our data indicate that the decrease in affinity caused by mutations in the fifth triplet repeat was similar to what was observed when either the $5^{\prime}$ side of the internal loop or the $3^{\prime}$ side of the hairpin loop was altered (Fig. 4). This finding suggests that each of the two potential TRAP-5'SL contacts has an energetic contribution roughly equivalent to one triplet repeat. Thus, the 5'SL might allow TRAP to bind the trp leader RNA two repeats sooner than if the leader only contained the triplet repeat region, thereby increasing the likelihood that tryptophan-activated TRAP would bind in time to promote termination. The comparison of $\mathrm{Kd}$ values for transcripts with or without the 5'SL (Fig. 2A) also suggested that the $5^{\prime} \mathrm{SL}$ is energetically equivalent to approximately two triplet repeats. A transcript with the 5'SL and four triplet repeats, for example, had the same $\mathrm{Kd}$ as an RNA with six repeats, but without the $5^{\prime} \mathrm{SL}$.

\section{Implications for in vivo function}

The number of TRAP molecules was estimated to be 200400 per cell, and this number did not change appreciably with growth phase or in the absence or presence of tryptophan (McCabe and Gollnick 2004). While the number of TRAP target transcripts in the cell at any given time is not known, overexpression of trp leader RNA on a plasmid leads to titration of TRAP (Gollnick et al. 2002, 2005). Thus, it appears that TRAP levels are balanced with the number of target transcripts to ensure tight control of gene expression in response to changes in the intracellular concentration of tryptophan.

It was recently shown that the rate of TRAP binding to RNA is a critical component of the trp operon attenua- tion mechanism (Barbolina et al. 2007). By increasing the affinity of TRAP for the nascent trp leader transcript, the 5 'SL reduces the number of downstream triplet repeats needed for tight binding, suggesting that this structure allows TRAP to bind earlier during transcription. Since the decision to terminate transcription is a time-sensitive process, the 5'SL may thereby lengthen the window of time in which TRAP can bind and promote termination. This effect was observed in our single-round transcription experiments, where mutation or deletion of the 5'SL resulted in a significant decrease in termination efficiency when transcription rates were fast (Fig. 6). Under these conditions, the 5'SL becomes critical for proper attenuation control. Since it is known that in vivo transcription rates are approximately fivefold faster than in vitro transcription rates with bacterial RNA polymerases (Uptain et al. 1997), this assay may understate the importance of the 5'SL.

Once bound, the interaction between TRAP and fulllength $\operatorname{trp}$ leader RNA is relatively strong $(\mathrm{Kd} \sim 1 \mathrm{nM})$, suggesting that TRAP would not readily dissociate from the RNA to allow its participation in another attenuation cycle if the intracellular tryptophan levels remain high. Indeed, the dissociation rate of TRAP complexed with RNAs containing the full 11 triplet repeats is very slow under these conditions (Baumann et al. 1996; data not shown). Because of this slow off-rate, exonucleolytic degradation of the terminated transcript by PNPase is required to recycle TRAP (Deikus et al. 2004). When TRAP is bound to all 11 triplet repeats, the $5^{\prime} \mathrm{SL}$ is probably not needed and may passively dissociate from the protein, or it might be displaced when the last few triplet repeats bind to TRAP. This interpretation would explain the observations that protection of the $5^{\prime} \mathrm{SL}$ was lost with 10 or 11 downstream repeats (Fig. 3A) and that the 5'SL had no effect on affinity with RNA containing 10 or 11 repeats (Fig. 2).

Organisms that are more distantly related to B. subtilis do not share the conserved G7, A8, A9, A19, and G20 nucleotides, raising the possibility that the mode of interaction between TRAP and the 5'SL in these organisms is different (or nonexistent). The Group 1 organisms, for example, have thermodynamically weak 5'SL structures that are rich in internal triplet repeats (Fig. 5). Since these internal repeats are appropriately spaced, it is possible that these organisms do not contain authentic 5'SL structures, and instead, the sequences function by providing additional triplet repeats with which TRAP can associate. Group 2 organisms have 5 'SLs that are structurally similar to those in Group 3 but have pyrimidine-rich single-stranded regions, particularly in the internal loop. However, this does not exclude the possibility that the loop and bulge in Group 2 5'SLs interact with their respective TRAP molecules. It is important to note that tryptophan biosynthesis genes are considered poor markers for characterizing an organism's overall evolutionary pathway (Brown and 
Doolittle 1997; Merkl 2007), and the phylogenetic relationships discussed here do not necessarily reflect genomic evolution (Gutierrez-Preciado et al. 2007).

While the absence of TRAP $(\Delta m t r B)$ abolished tryptophan-dependent regulation, deletion of the $5^{\prime} \mathrm{SL}$ in the $\Delta m t r B$ background showed a further threefold increase in expression (Fig. 4). This phenomenon was observed previously (Sudershana et al. 1999), where it was proposed that the $5^{\prime} \mathrm{SL}$ could play a role in message stability in a TRAP-independent pathway. If, for example, the 5'SL acts as a signal for transcript degradation, loss of the $5^{\prime} \mathrm{SL}$ would lead to the observed increase in expression. In some instances it was shown that mRNA stability is directly related to the $5^{\prime}$ regions of B. subtilis transcripts (Melin et al. 1990; Condon et al. 1996; Bechhofer and Wang 1998). Furthermore, it was recently shown that B. subtilis may utilize a $5^{\prime}$ to $3^{\prime}$ exonuclease to degrade transcripts (Mathy et al. 2007). If this enzyme participates in the degradation of $\operatorname{trp}$ leader RNA, the $5^{\prime} \mathrm{SL}$ might stimulate this process.

\section{Conclusions}

The experiments described here have allowed us to refine the model of TRAP-RNA interaction during trp operon attenuation. As the $5^{\prime}$ end of the transcript emerges from RNAP, the 5'SL folds. Once a sufficient number of triplet repeats emerge from the transcribing polymerase (e.g., three or four repeats), TRAP binds to the nascent trp leader transcript by contacting the top of the hairpin, the 5 ' side of the internal loop, and the emerging triplet repeats (i.e., it appears that the initial stable interaction requires both the 5'SL and the first few triplets). The nature of these contacts presumably orients the protein so that the RNA can easily wrap around its periphery as transcription continues. TRAP would continue to bind the remaining repeats in a $5^{\prime}$ to $3^{\prime}$ directionality as they emerge from RNAP (Barbolina et al. 2005). As the 10th and 11th repeats bind, dissociation of the TRAP-RNA complex before the terminator forms would be virtually impossible, and the $5^{\prime} \mathrm{SL}$ is displaced as a consequence of the geometry of the TRAP-RNA complex, in which TRAP is completely encircled by RNA. After the transcript terminates, PNPase (and possibly other nucleolytic factors) turn over the TRAP-RNA complex, allowing the protein to function in another cycle of transcription attenuation.

\section{MATERIALS AND METHODS}

\section{Bacterial strains and plasmids}

All plasmids and B. subtilis strains used in these studies are described in Table 1. Plasmids pPB1101 through pPB1110 and pAM1 were prepared by cloning B. subtilis trp leader sequences of the desired length into the ScaI and BamHI sites of the pTZ18U vector (United States Biochemical Corp.). DNA tem- plates for in vitro transcription with T7 RNAP were obtained by PCR amplification of pPB77 (Babitzke et al. 1994) using primers selective to the region of interest. 5'SL mutants were analyzed with Mfold (Zuker 2003) using the default parameters prior to synthesis to ensure that they did not lead to any alternate 5'SL conformations. Sequencing revealed that the previously reported A19U mutation was incorrect (Sudershana et al. 1999). This mutant was corrected and reanalyzed. Plasmids pAM2 to pAM21 were obtained using the QuikChange mutagenesis strategy (Stratagene), with slight modifications. Mutagenic primers were designed such that the mutated nucleotide was on the $5^{\prime}$ end of the top-strand primer, while the $5^{\prime}$ end of the bottom-strand primers terminated immediately prior to the mutation site. Oligos were phosphorylated with T4 polynucleotide kinase (New England Biolabs), followed by PCR amplification using pPB1105 as template. The resulting PCR products were ligated, treated with DpnI to remove template DNA, and transformed into E. coli DH5 $\alpha$. All plasmids were sequenced prior to performing run-off transcription reactions.

B. subtilis strains PLBS601 through PLBS606 were constructed by ligating the 730-bp EcoRI-HindIII fragment containing the trp leader with the mutation of interest into the ptrpBGI-PLK vector (Merino et al. 1995), placing lac $Z$ expression under control of the trp promoter and leader region. After sequencing, plasmids were linearized with PstI and integrated into the nonessential amyE locus of the B. subtilis chromosome. Proper integration was confirmed by the starch-iodine test (Sekiguchi et al. 1975) and sequencing of PCR-amplified chromosomal DNA.

\section{TRAP purification and RNA synthesis}

TRAP was purified as described previously (Yakhnin et al. 2000). BamHI linearized plasmids were used as templates for in vitro transcription reactions. Templates for RNAs lacking the 5'SL were generated by PCR using a common top-strand primer containing a T7 promoter and a region complementary to residues +33 to +49 of the leader DNA and bottom-strand primers complementary to the trp leader, such that the desired number of downstream repeats would be incorporated into the PCR product. Plasmid pAM1 was used as template. DNA fragments were purified on 3\% NuSieve GTG gels (Cambrex) prior to RNA synthesis.

In vitro generated transcripts for subsequent biochemical analyses were produced using the MEGAscript kit (Ambion). DNA templates were removed by the addition of $2 \mathrm{U}$ turboDNase (Ambion) and incubating at $37^{\circ} \mathrm{C}$ for $30 \mathrm{~min}$. Unincorporated nucleotides were removed by passing the reaction mixture through Mini Quick Spin RNA columns (Roche). The eluent was extracted with phenol/chloroform and the RNA was ethanol precipitated. Transcripts were resuspended, dephosphorylated, and $5^{\prime}$-end labeled with $\left[\gamma^{-32} \mathrm{P}\right]$ ATP (Perkin-Elmer). Labeled RNAs were purified on denaturing $6 \%$ polyacrylamide gels, extracted with phenol/chloroform, ethanol precipitated, and resuspended in TE buffer $(10 \mathrm{mM}$ Tris- $\mathrm{HCl}$ at $\mathrm{pH} 7.5,1 \mathrm{mM}$ EDTA). RNAs were quantified using scintillation counting. Prior to all analyses, RNAs were renatured by heating to $90^{\circ} \mathrm{C}$ for $1 \mathrm{~min}$ in $50 \mathrm{mM} \mathrm{KCl}$, followed by slow cooling to room temperature.

\section{Filter binding and gel mobility shift assays}

Gel mobility shift assays were performed as described previously (Yakhnin et al. 2004). Filter-binding reaction mixtures $(45 \mu \mathrm{L})$ 
TABLE 1. B. subtilis strains and plasmids

\begin{tabular}{|c|c|c|}
\hline Strain or plasmid & Description & Source or reference \\
\hline \multicolumn{3}{|l|}{ Strains ${ }^{\mathrm{a}}$} \\
\hline PLBS44 & amyE:: $\left[\operatorname{trp} P(-412\right.$ to +203$\left.) \operatorname{trp} E^{\prime}--^{\prime} l a c Z \mathrm{Cm}^{r}\right]$ & Sudershana et al. (1999) \\
\hline PLBS104 & amyE:: $\left[\operatorname{trp} P(-412\right.$ to +203$) \Delta(+3$ to +32$\left.) \operatorname{trp} E^{\prime}-{ }^{\prime} l a c Z \mathrm{Cm}^{\mathrm{r}}\right]$ & Sudershana et al. (1999) \\
\hline PLBS251 & $\Delta m \operatorname{tr} B \arg C 4$ amyE:: $\left[\operatorname{trp} P(-412\right.$ to +203$\left.) \operatorname{trp} E^{\prime}-{ }^{\prime} l a c Z \mathrm{Cm}^{\mathrm{r}}\right]$ & Sudershana et al. (1999) \\
\hline PLBS252 & $\Delta m \operatorname{tr} B \arg C 4$ amyE: $:\left[\operatorname{trp} P(-412\right.$ to +203$) \Delta(+3$ to +32$) \operatorname{trp} E^{\prime}-{ }^{\prime}$ lac $\left.Z \mathrm{Cm}^{\mathrm{r}}\right]$ & Sudershana et al. (1999) \\
\hline PLBS259 & amyE::[trpP(-412 to +203) G7A $\left.\operatorname{trp} E^{\prime}-{ }^{\prime} l a c Z \mathrm{Cm}^{\mathrm{r}}\right]$ & Sudershana et al. (1999) \\
\hline PLBS601 & amyE:: $\left[\operatorname{trp} P(-412\right.$ to +203$\left.) \mathrm{A} 8 \mathrm{G} \operatorname{trp} E^{\prime}-{ }^{\prime} / a c Z \mathrm{Cm}^{\mathrm{r}}\right]$ & This study \\
\hline PLBS602 & amyE:: $\left[\operatorname{trp} P(-412\right.$ to +203$)$ A9G $\left.\operatorname{trp} E^{\prime}-{ }^{\prime} l a c Z \mathrm{Cm}^{\mathrm{r}}\right]$ & This study \\
\hline PLBS603 & amyE:: $\left[\operatorname{trp} P(-412\right.$ to +203$\left.) \mathrm{A} 17 \mathrm{U} \operatorname{trp} E^{\prime}-{ }^{\prime} l a c Z \mathrm{Cm}^{\mathrm{r}}\right]$ & This study \\
\hline PLBS604 & amyE::[trpP(-412 to +203) A19U trpE'-'lacZ $\left.\mathrm{Cm}^{\mathrm{r}}\right]$ & This study \\
\hline PLBS605 & amyE:: $\left[\operatorname{trp} P(-412\right.$ to +203$\left.) \mathrm{G} 20 \mathrm{~A} \operatorname{trp} E^{\prime}-{ }^{\prime} l a c Z \mathrm{Cm}^{\mathrm{r}}\right]$ & This study \\
\hline PLBS606 & amyE:: $\left[\operatorname{trp} P(-412\right.$ to +203$\left.) \mathrm{A} 30 \mathrm{U} \operatorname{trp} E^{\prime}-{ }^{\prime} l a c Z \mathrm{Cm}^{r}\right]$ & This study \\
\hline \multicolumn{3}{|c|}{ 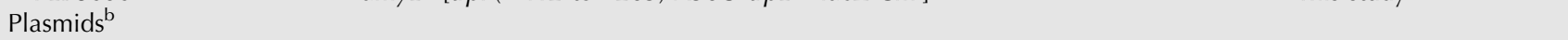 } \\
\hline pPB77 & +1 to +111 of $\operatorname{trp}$ leader & Babitzke et al. (1994) \\
\hline pPB1101 & +1 to +38 of $\operatorname{trp}$ leader $\left(5^{\prime} \mathrm{SL}-1\right)$ & This study \\
\hline pPB1102 & +1 to +44 of $\operatorname{trp}$ leader $\left(5^{\prime} \mathrm{SL}-2\right)$ & This study \\
\hline pPB1103 & +1 to +49 of $\operatorname{trp}$ leader $\left(5^{\prime} \mathrm{SL}-3\right)$ & This study \\
\hline pPB1104 & +1 to +55 of $\operatorname{trp}$ leader $\left(5^{\prime} \mathrm{SL}-4\right)$ & This study \\
\hline pPB1105 & +1 to +60 of $\operatorname{trp}$ leader (5'SL-5) & This study \\
\hline pPB1106 & +1 to +65 of $\operatorname{trp}$ leader ( $\left.5^{\prime} \mathrm{SL}-6\right)$ & This study \\
\hline pPB1107 & +1 to +70 of $\operatorname{trp}$ leader $\left(5^{\prime} \mathrm{SL}-7\right)$ & This study \\
\hline pPB1108 & +1 to +76 of $\operatorname{trp}$ leader $\left(5^{\prime} \mathrm{SL}-8\right)$ & This study \\
\hline pPB1109 & +1 to +81 of $\operatorname{trp}$ leader ( $\left.5^{\prime} \mathrm{SL}-9\right)$ & This study \\
\hline pPB1110 & +1 to +86 of $\operatorname{trp}$ leader $\left(5^{\prime} \mathrm{SL}-10\right)$ & This study \\
\hline pAM1 & +1 to +91 of $\operatorname{trp}$ leader $\left(5^{\prime} \mathrm{SL}-11\right)$ & This study \\
\hline pAM2 & +1 to +60 of $\operatorname{trp}$ leader (5'SL-5 G7A) & This study \\
\hline pAM3 & +1 to +60 of $\operatorname{trp}$ leader (5'SL-5 A6C) & This study \\
\hline pAM4 & +1 to +60 of $\operatorname{trp}$ leader (5'SL-5 A19U) & This study \\
\hline pAM5 & +1 to +60 of $\operatorname{trp}$ leader ( $\left.5^{\prime} \mathrm{SL}-5 \mathrm{C} 3 \mathrm{G}\right)$ & This study \\
\hline pAM6 & +1 to +60 of $\operatorname{trp}$ leader ( $5^{\prime}$ SL-5 G31C) & This study \\
\hline pAM7 & +1 to +60 of $\operatorname{trp}$ leader (5'SL-5 A30U) & This study \\
\hline pAM8 & +1 to +60 of $\operatorname{trp}$ leader ( $\left.5^{\prime} \mathrm{SL}-5 \mathrm{U} 5 \mathrm{~A}\right)$ & This study \\
\hline pAM9 & +1 to +60 of $\operatorname{trp}$ leader ( $\left.5^{\prime} \mathrm{SL}-5 \mathrm{U} 4 \mathrm{~A}\right)$ & This study \\
\hline pAM10 & +1 to +60 of $\operatorname{trp}$ leader (5'SL-5 A29U) & This study \\
\hline pAM11 & +1 to +60 of $\operatorname{trp}$ leader (5'SL-5 C3G:G31C) & This study \\
\hline $\mathrm{pAM} 12$ & +1 to +60 of $\operatorname{trp}$ leader (5'SL-5 A17U:A19U) & This study \\
\hline pAM13 & +1 to +60 of trp leader (5'SL-5 U5A:A29U) & This study \\
\hline pAM14 & +1 to +60 of $\operatorname{trp}$ leader (5'SL-5 U4A:A30U) & This study \\
\hline pAM15 & +1 to +60 of $\operatorname{trp}$ leader $\left(5^{\prime} \mathrm{SL}-5 \mathrm{~A} 17 \mathrm{U}\right)$ & This study \\
\hline pAM16 & +1 to +60 of $\operatorname{trp}$ leader $\left(5^{\prime} \mathrm{SL}-5 \mathrm{G} 18 \mathrm{~A}\right)$ & This study \\
\hline $\mathrm{pAM} 17$ & +1 to +60 of $\operatorname{trp}$ leader $\left(5^{\prime}\right.$ SL-5 G20A) & This study \\
\hline pAM18 & +1 to +60 of $\operatorname{trp}$ leader (5'SL-5 G18A:G20A) & This study \\
\hline pAM19 & +1 to +60 of $\operatorname{trp}$ leader (5'SL-5 A8G) & This study \\
\hline pAM20 & +1 to +60 of trp leader (5'SL-5 A9G) & This study \\
\hline pAM21 & +1 to +60 of $\operatorname{trp}$ leader $\left(5^{\prime} \mathrm{SL}-5 \mathrm{~A} 28 \mathrm{G}\right)$ & This study \\
\hline
\end{tabular}

a trpP denotes the trp operon promoter. Prime indicates truncation of the gene. Numbers in parentheses correspond to the trp leader and neighboring nucleotides that were incorporated into each translational fusion relative to the transcriptional start site $(+1)$. $(\Delta)$ Deletion of the indicated nucleotides or gene.

${ }^{b}$ Numbers correspond to the trp leader region that was cloned into each plasmid relative to the transcriptional start site $(+1)$. Information in parentheses indicates the number of triplet repeats downstream from the $5^{\prime} \mathrm{SL}$ in each plasmid and/or mutations within the $5^{\prime} \mathrm{SL}$.

contained $1 \mathrm{mM}$ L-tryptophan, $40 \mathrm{mM}$ Tris- $\mathrm{HCl}$ ( $\mathrm{pH} 8.0$ ), $250 \mathrm{mM} \mathrm{KCl}, 4 \mathrm{mM} \mathrm{MgCl} 2,10 \%$ glycerol, $0.2 \mathrm{mg} / \mathrm{mL}$ E. coli tRNA, $0.01 \mathrm{nM}$ labeled RNA, and various concentrations of purified TRAP. Reactions were incubated at $37^{\circ} \mathrm{C}$ for $25 \mathrm{~min}$ prior to filtration through $0.2 \mu \mathrm{m}$ nitrocellulose (Whatman) and Hybond-N+ (Amersham) membranes using a 96-well Spot-Blot apparatus (Schleicher \& Schuell). After filtering, wells were washed with an equal volume of reaction buffer. Membranes were dried and imaged on a Typhoon 8600 Variable Mode Imager (Molecular Dynamics) and quantified using Imagequant 5.2 (Molecular Dynamics). For a given protein concentration, values corresponding to the fraction of bound RNA were averaged and standard deviations were calculated from at least two independent experiments performed in duplicate. The fraction of RNA bound was plotted as a function of TRAP concentration using Kaleidagraph 3.6 (Synergy Software) and fit to the binding equation 
$\mathrm{f}_{\text {bound }}=\mathrm{f}_{\max }[\mathrm{TRAP}] /([\mathrm{TRAP}]+\mathrm{Kd})$; where $\mathrm{Kd}$ is the dissociation binding constant and $\mathrm{f}_{\max }$ is the maximum fraction of bound RNA. Fits were weighted to the standard deviation of each data point. The addition of a Hill coefficient to the binding equation did not significantly alter Kd values or improve the coefficient of variation to the fit, and was excluded in the final analyses.

\section{RNA footprinting assay}

Binding reactions $(5 \mu \mathrm{L})$ contained $40 \mathrm{mM}$ Tris $-\mathrm{HCl}(\mathrm{pH} 8.0)$, $250 \mathrm{mM} \mathrm{KCl}, 4 \mathrm{mM} \mathrm{MgCl}, 32.5 \mathrm{ng}$ yeast RNA, $100 \mu \mathrm{g}$ bovine serum albumin, $7.5 \%$ glycerol, $1 \mathrm{mM}$ L-tryptophan, $0.5 \mathrm{nM}$ labeled RNA, and either 10- or 100-fold excess of TRAP (relative to the $\mathrm{Kd}$ ). It was not possible to use a 100-fold excess of TRAP with the weak-binding transcripts, as the solubility of TRAP was limiting. Reactions were incubated at $37^{\circ} \mathrm{C}$ for $10 \mathrm{~min}$, followed by the addition of $0.04 \mathrm{U}$ RNase $\mathrm{T}_{1}$ (Roche), 0.1 U RNase $\mathrm{T}_{2}$ (Sigma), $8 \times 10^{-6} \mathrm{U}_{\text {RNase }} \mathrm{V}_{1}$ (Pierce), or $1 \times 10^{-6} \mathrm{mg}$ RNase A (Ambion). Titrations were performed to identify the amount of enzyme in which $\sim 90 \%$ of the transcripts were uncleaved to minimize multiple cleavages in any one transcript. TRAP-RNA complexes were incubated with the desired nuclease for $15 \mathrm{~min}$ at $37^{\circ} \mathrm{C}$ prior to stopping the reaction by adding $5 \mu \mathrm{L}$ of $2 \times$ loading buffer $(95 \%$ formamide, $0.2 \%$ SDS, $20 \mathrm{mM}$ EDTA, $0.025 \%$ bromophenol blue, and $0.025 \%$ xylene cyanol). Samples were fractionated through $12 \%$ denaturing sequencing gels and visualized using a PhosphorImager.

\section{Single-round in vitro transcription assay}

Halted transcription elongation complexes were created as described previously (Babitzke et al. 2003). Briefly, B. subtilis RNAP was incubated with the template of interest in $1 \mathrm{x}$ transcription buffer ( $40 \mathrm{mM}$ Tris- $\mathrm{HCl}$ ( $\mathrm{pH} 8.0$ ), $4 \mathrm{mM} \mathrm{MgCl}_{2}, 0.6 \mathrm{mM}$ EDTA, $4 \%$ trehalose, and $30 \mathrm{mM}$ DTT) with $8 \mu \mathrm{M}$ ATP and UTP, $2 \mu \mathrm{M}$ $\mathrm{GTP}$, and $10 \mu \mathrm{Ci}\left[\alpha-{ }^{32} \mathrm{P}\right] \mathrm{UTP}$ (Perkin-Elmer). Inclusion of an ApGpC RNA primer in the absence of CTP resulted in halted elongation complexes following synthesis of the A residue at +12 . These complexes were stable for several hours on ice and elongation was resumed with warming and the addition of CTP. Extension mixtures were assembled on ice and yielded final concentrations of $100 \mathrm{nM}$ TRAP, $1 \mathrm{mM}$ L-tryptophan, $0.1 \mathrm{mg} / \mathrm{mL}$ heparin, and NTPs $(8-500 \mu \mathrm{M})$ in $1 \mathrm{x}$ transcription buffer. Both halted elongation complexes and extension mixtures were preincubated at $37^{\circ} \mathrm{C}$ for $5 \mathrm{~min}$. A total of $4.5 \mu \mathrm{L}$ of the halted elongation complex was added to $3 \mu \mathrm{L}$ of the extension mixture. Reactions were incubated for $30 \mathrm{~min}$ at $37^{\circ} \mathrm{C}$, then stopped with the addition of an equal volume of $2 \mathrm{x}$ loading buffer. Quenched reactions were heated for $5 \mathrm{~min}$ at $95^{\circ} \mathrm{C}$ and resolved on $6 \%$ denaturing polyacrylamide gels. Readthrough and terminated products were quantified using a PhosphorImager. Values for percent termination were corrected for the different number of labeling sites in the readthrough and terminated transcripts. The templates occasionally yielded a second set of bands corresponding to initiation from a cryptic promoter within the 5'SL (data not shown). These bands have been observed and characterized previously (Yakhnin et al. 2006a) and were excluded from quantification.

\section{$\beta$-galactosidase expression assay}

$\beta$-galactosidase assays were performed as described previously (Sudershana et al. 1999). Cultures were grown to late exponential phase (Klett 110, no. 54 green filter) in minimal acid hydrolyzed casein $(\mathrm{ACH})$ medium $(0.2 \%)$ in the presence or absence of $50 \mu \mathrm{g} / \mathrm{mL} \mathrm{L}$-tryptophan. Aliquots were assayed for $\beta$-galactosidase activity as described previously (Miller 1972).

\section{Phylogenetic analysis}

A BLAST search (Altschul et al. 1990) identified 14 organisms that contained a potential TRAP-binding site preceding the gene encoding TrpE (anthranilate synthase I), suggesting that regulation of these trp operons occurred via a TRAP-mediated attenuation mechanism. Leader sequences were analyzed with Mfold to determine the structures of the predicted terminator, antiterminator, and $5^{\prime} \mathrm{SL}$. For each of the 11 organisms containing a $5^{\prime} \mathrm{SL}$, the protein sequences of the tryptophan biosynthesis enzymes were obtained from GenBank, concatenated to yield a single-peptide sequence and aligned using ClustalX 1.81 (Thompson et al. 1997). Since the complete genomes were not available for several organisms of interest, only sequences from TrpE and TrpD were used to construct the tree. Aligned sequences were visually inspected and degapped using BioEdit 7.0.5 (Hall 1999) and then imported into PHYLIP 3.66 (Felsenstein 1989). The node containing the E. coli and S. typhimurium branches was set as the outgroup. Data were bootstrapped 1000 times prior to sequentially importing aligned sequences into the Protdist, Neighbor, and Consense subprograms using the default parameters. Free energy values for the predicted $5^{\prime}$ SL structures were calculated at $37^{\circ} \mathrm{C}$ using Mfold.

\section{ACKNOWLEDGMENTS}

We thank Alexander Yakhnin, Hong Zhang, and Bhavana Achary for technical assistance and Paul Gollnick for critical reading of the manuscript. This work was supported by grants GM52840 to P.B. and GM58709 to P.C.B. from the National Institutes of Health.

Received July 5, 2007; accepted August 15, 2007.

\section{REFERENCES}

Altschul, S.F., Gish, W., Miller, W., Myers, E.W., and Lipman, D.J. 1990. Basic local alignment search tool. J. Mol. Biol. 215: 403-410.

Antson, A.A., Otridge, J., Brzozowski, A.M., Dodson, E.J., Dodson, G.G., Wilson, K.S., Smith, T.M., Yang, M., Kurecki, T., and Gollnick, P. 1995. The structure of $\operatorname{trp}$ RNA-binding attenuation protein. Nature 374: 693-700.

Antson, A.A., Dodson, E.J., Dodson, G., Greaves, R.B., Chen, X., and Gollnick, P. 1999. Structure of the trp RNA-binding attenuation protein, TRAP, bound to RNA. Nature 401: 235-242.

Babitzke, P. 1997. Regulation of tryptophan biosynthesis: Trp-ing the TRAP or how Bacillus subtilis reinvented the wheel. Mol. Microbiol. 26: $1-9$.

Babitzke, P. 2004. Regulation of transcription attenuation and translation initiation by allosteric control of an RNA-binding protein: The Bacillus subtilis TRAP protein. Curr. Opin. Microbiol. 7: 132139.

Babitzke, P. and Yanofsky, C. 1993. Reconstitution of Bacillus subtilis $\operatorname{trp}$ attenuation in vitro with TRAP, the $\operatorname{trp}$ RNA-binding attenuation protein. Proc. Natl. Acad. Sci. 90: 133-137.

Babitzke, P., Stults, J.T., Shire, S.J., and Yanofsky, C. 1994. TRAP, the trp RNA-binding attenuation protein of Bacillus subtilis, is a 
multisubunit complex that appears to recognize G/UAG repeats in the $\operatorname{trpEDCFBA}$ and $\operatorname{trp} G$ transcripts. J. Biol. Chem. 269: 1659716604

Babitzke, P., Bear, D.G., and Yanofsky, C. 1995. TRAP, the trp RNAbinding attenuation protein of Bacillus subtilis, is a toroid-shaped molecule that binds transcripts containing GAG or UAG repeats separated by two nucleotides. Proc. Natl. Acad. Sci. 92: 7916-7920.

Babitzke, P., Yealy, J., and Campanelli, D. 1996. Interaction of the trp RNA-binding attenuation protein (TRAP) of Bacillus subtilis with RNA: Effects of the number of GAG repeats, the nucleotides separating adjacent repeats, and RNA secondary structure. $J$. Bacteriol. 178: 5159-5163.

Babitzke, P., Schaak, J., Yakhnin, A.V., and Bevilacqua, P.C. 2003. Role of RNA structure in transcription attenuation in Bacillus subtilis: The $\operatorname{trpEDCFBA}$ operon as a model system. Methods Enzymol. 371: 392-404.

Barbolina, M.V., Li, X., and Gollnick, P. 2005. Bacillus subtilis TRAP binds to its RNA target by a $5^{\prime}$ to $3^{\prime}$ directional mechanism. J. Mol. Biol. 345: 667-679.

Barbolina, M.V., Kristoforov, R., Manfredo, A., Chen, Y., and Gollnick, P. 2007. The rate of TRAP binding to RNA is crucial for the transcription attenuation control of the B. subtilis trp operon. J. Mol. Biol. 370: 925-938.

Baumann, C., Otridge, J., and Gollnick, P. 1996. Kinetic and thermodynamic analysis of the interaction between TRAP (trp RNA-binding attenuation protein) of Bacillus subtilis and trp leader RNA. J. Biol. Chem. 271: 12269-12274.

Baumann, C., Xirasager, S., and Gollnick, P. 1997. The trp RNAbinding attenuation protein (TRAP) from Bacillus subtilis binds to unstacked trp leader RNA. J. Biol. Chem. 272: 19863-19869.

Bechhofer, D.H. and Wang, W. 1998. Decay of ermC mRNA in a polynucleotide phosphorylase mutant of Bacillus subtilis. J. Bacteriol. 180: 5968-5977.

Bevilacqua, J.M. and Bevilacqua, P.C. 1998. Thermodynamic analysis of an RNA combinatorial library contained in a short hairpin. Biochemistry 37: 15877-15884.

Brown, J.R. and Doolittle, W.F. 1997. Archaea and the prokaryote-toeukaryote transition. Microbiol. Mol. Biol. Rev. 61: 456-502.

Condon, C., Putzer, H., and Grunberg-Manago, M. 1996. Processing of the leader mRNA plays a major role in the induction of thrS expression following threonine starvation in Bacillus subtilis. Proc. Natl. Acad. Sci. 93: 6992-6997.

Deikus, G., Babitzke, P., and Bechhofer, D.H. 2004. Recycling of a regulatory protein by degradation of the RNA to which it binds. Proc. Natl. Acad. Sci. 101: 2747-2751.

Du, H. and Babitzke, P. 1998. $\operatorname{trp}$ RNA-binding attenuation proteinmediated long distance RNA refolding regulates translation of $\operatorname{trp} E$ in Bacillus subtilis. J. Biol. Chem. 273: 20494-20503.

Du, H., Tarpey, R., and Babitzke, P. 1997. The trp RNA-binding attenuation protein regulates $\operatorname{TrpG}$ synthesis by binding to the $\operatorname{trp} G$ ribosome binding site of Bacillus subtilis. J. Bacteriol. 179: 2582-2586.

Du, H., Yakhnin, A.V., Dharmaraj, S., and Babitzke, P. 2000. $\operatorname{trp}$ RNAbinding attenuation protein-5' stem-loop RNA interaction is required for proper transcription attenuation control of the Bacillus subtilis trpEDCFBA operon. J. Bacteriol. 182: 1819-1827.

Elliott, M.B., Gottlieb, P.A., and Gollnick, P. 2001. The mechanism of RNA binding to TRAP: Initiation and cooperative interactions. RNA 7: 85-93.

Felsenstein, J. 1989. PHYLIP-Phylogeny Inference Package (Version 3.2). Cladistics 5: 164-166.

Gollnick, P. 1994. Regulation of the Bacillus subtilis trp operon by an RNA-binding protein. Mol. Microbiol. 11: 991-997.

Gollnick, P., Ishino, S., Kuroda, M.I., Henner, D.J., and Yanofsky, C. 1990. The $m t r$ locus is a two-gene operon required for transcription attenuation in the trp operon of Bacillus subtilis. Proc. Natl. Acad. Sci. 87: 8726-8730.

Gollnick, P., Babitzke, P., Merino, E., and Yanofsky, C. 2002. Aromatic amino acid metabolism in Bacillus subtilis. In Bacillus subtilis and its closest relatives: From genes to cells (ed. A.L. Sonenshein), 233-244 ASM Press. Washington, D.C.

Gollnick, P., Babitzke, P., Antson, A., and Yanofsky, C. 2005. Complexity in regulation of tryptophan biosynthesis in Bacillus subtilis. Annu. Rev. Genet. 39: 47-68.

Gutierrez-Preciado, A., Yanofsky, C., and Merino, E. 2007. Comparison of tryptophan biosynthetic operon regulation in different Gram-positive bacterial species. Trends Genet. 23: 422-427.

Hall, T.A. 1999. BioEdit: A user-friendly biological sequence alignment editor and analysis program for Windows 95/98/NT. Nucleic Acids Symp. Ser. 41: 95-98.

Hopcroft, N.H., Manfredo, A., Wendt, A.L., Brzozowski, A.M., Gollnick, P., and Antson, A.A. 2004. The interaction of RNA with TRAP: The role of triplet repeats and separating spacer nucleotides. J. Mol. Biol. 338: 43-53.

Kierzek, R., Burkard, M.E., and Turner, D.H. 1999. Thermodynamics of single mismatches in RNA duplexes. Biochemistry 38: 14214-14223.

Lee, J.C., Gutell, R.R., and Russell, R. 2006. The UAA/GAN internal loop motif: A new RNA structural element that forms a crossstrand AAA stack and long-range tertiary interactions. J. Mol. Biol. 360: 978-988.

Mathy, N., Benard, L., Pellegrini, O., Daou, R., Wen, T., and Condon, C. 2007. 5'-to-3' exoribonuclease activity in bacteria: Role of RNase J1 in rRNA maturation and 5' stability of mRNA. Cell 129: 681-692.

McCabe, B.C. and Gollnick, P. 2004. Cellular levels of trp RNAbinding attenuation protein in Bacillus subtilis. J. Bacteriol. 186: 5157-5159.

McDowell, J.C., Roberts, J.W., Jin, D.J., and Gross, C. 1994. Determination of intrinsic transcription termination efficiency by RNA polymerase elongation rate. Science 266: 822-825.

McElroy, C.A., Manfredo, A., Gollnick, P., and Foster, M.P. 2006. Thermodynamics of tryptophan-mediated activation of the $\operatorname{trp}$ RNA-binding attenuation protein. Biochemistry 45: 7844-7853.

Melin, L., Friden, H., Dehlin, E., Rutberg, L., and von Gabain, A. 1990. The importance of the $5^{\prime}$-region in regulating the stability of sdh mRNA in Bacillus subtilis. Mol. Microbiol. 4: 1881-1889.

Merino, E. and Yanofsky, C. 2005. Transcription attenuation: A highly conserved regulatory strategy used by bacteria. Trends Genet. 21: 260-264.

Merino, E., Babitzke, P., and Yanofsky, C. 1995. $\operatorname{trp}$ RNA-binding attenuation protein (TRAP)-trp leader RNA interactions mediate translational as well as transcriptional regulation of the Bacillus subtilis trp operon. J. Bacteriol. 177: 6362-6370.

Merkl, R. 2007. Modeling the evolution of the archeal tryptophan synthase. BMC Evol. Biol. 7: 59.

Miller, J.H. 1972. Experiments in molecular genetics. Cold Spring Harbor Laboratory Press, Cold Spring Harbor, New York.

Morse, S.E. and Draper, D.E. 1995. Purine-purine mismatches in RNA helices: Evidence for protonated G.A pairs and next-nearestneighbor effects. Nucleic Acids Res. 23: 302-306.

Salehi-Ashtiani, K., Luptak, A., Litovchick, A., and Szostak, J.W. 2006. A genomewide search for ribozymes reveals an HDV-like sequence in the human CPEB3 gene. Science 313: 1788-1792.

Sarsero, J.P., Merino, E., and Yanofsky, C. 2000a. A Bacillus subtilis gene of previously unknown function, $y h a G$, is translationally regulated by tryptophan-activated TRAP, and appears to be concerned with tryptophan transport. J. Bacteriol. 182: 2329-2331.

Sarsero, J.P., Merino, E., and Yanofsky, C. 2000b. A Bacillus subtilis operon containing genes of unknown function senses tRNAtrp charging and regulates expression of the genes for tryptophan biosynthesis. Proc. Natl. Acad. Sci. 97: 2656-2661.

Sekiguchi, J., Takada, N., and Okada, H. 1975. Genes affecting the productivity of $\alpha$-amylase in Bacillus subtilis Marburg. J. Bacteriol. 121: 688-694.

Sudershana, S., Du, H., Mahalanabis, M., and Babitzke, P. 1999. A 5 ' RNA stem-loop participates in the transcription attenuation mechanism that controls expression of the Bacillus subtilis trpEDCFBA operon. J. Bacteriol. 181: 5742-5749. 
Szigeti, R., Milescu, M., and Gollnick, P. 2004. Regulation of the tryptophan biosynthetic genes in Bacillus halodurans: Common elements but different strategies than those used by Bacillus subtilis. J. Bacteriol. 186: 818-828.

Thompson, J.D., Gibson, T.J., Plewniak, F., Jeanmougin, F., and Higgins, D.G. 1997. The CLUSTAL_X windows interface: Flexible strategies for multiple sequence alignment aided by quality analysis tools. Nucleic Acids Res. 25: 4876-4882. doi: 10.1093/nar/25.24.4876.

Uptain, S.M., Kane, C.M., and Chamberlin, M.J. 1997. Basic mechanisms of transcript elongation and its regulation. Annu. Rev. Biochem. 66: 117-172.

Yakhnin, A.V. and Babitzke, P. 2002. NusA-stimulated RNA polymerase pausing and termination participates in the Bacillus subtilis trp operon attenuation mechanism in vitro. Proc. Natl. Acad. Sci. 99: 11067-11072.

Yakhnin, A.V., Trimble, J.J., Chiaro, C.R., and Babitzke, P. 2000. Effects of mutations in the L-tryptophan binding pocket of the trp RNA-binding attenuation protein of Bacillus subtilis. J. Biol. Chem. 275: 4519-4524.

Yakhnin, H., Zhang, H., Yakhnin, A.V., and Babitzke, P. 2004. The trp RNA-binding attenuation protein of Bacillus subtilis regulates translation of the tryptophan transport gene $\operatorname{trpP}(y h a G)$ by blocking ribosome binding. J. Bacteriol. 186: 278-286.

Yakhnin, A.V., Yakhnin, H., and Babitzke, P. 2006a. RNA polymerase pausing regulates translation initiation by providing additional time for TRAP-RNA interaction. Mol. Cell 24: 547-557.
Yakhnin, H., Yakhnin, A.V., and Babitzke, P. 2006b. The trp RNAbinding attenuation protein (TRAP) of Bacillus subtilis regulates translation initiation of $y c b K$, a gene encoding a putative efflux protein, by blocking ribosome binding. Mol. Microbiol. 61: 12521266.

Yakhnin, H., Yakhnin, A.V., and Babitzke, P. 2007. Translation control of $\operatorname{trp} G$ from transcripts originating from the folate operon promoter of Bacillus subtilis is influenced by translation-mediated displacement of bound TRAP, while translation control of transcripts originating from a newly identified $\operatorname{trp} G$ promoter is not. J. Bacteriol. 189: 872-879.

Yang, M., de Saizieu, A., VanLoon, A.P.G.M., and Gollnick, P. 1995. Translation of $\operatorname{trp} G$ in Bacillus subtilis is regulated by the $\operatorname{trp}$ RNAbinding attenuation protein (TRAP). J. Bacteriol. 177: 4272-4278.

Yang, M., Chen, X.-P., and Gollnick, P. 1997. Alanine-scanning mutagenesis of Bacillus subtilis trp RNA-binding attenuation protein (TRAP) reveals residues involved in tryptophan binding and RNA binding. J. Mol. Biol. 270: 696-710.

Yanofsky, C. 2000. Transcription attenuation: Once viewed as a novel regulatory strategy. J. Bacteriol. 182: 1-8.

Yanofsky, C. and Crawford, I.P. 1987. The tryptophan operon. In Escherichia coli and Salmonella typhimurium (eds. F.C. Neidhardt et al.), 1453-1472. ASM Press, Washington, DC.

Zuker, M. 2003. Mfold web server for nucleic acid folding and hybridization prediction. Nucleic Acids Res. 31: 3406-3415. doi: 10.1093/nar/gkg595. 

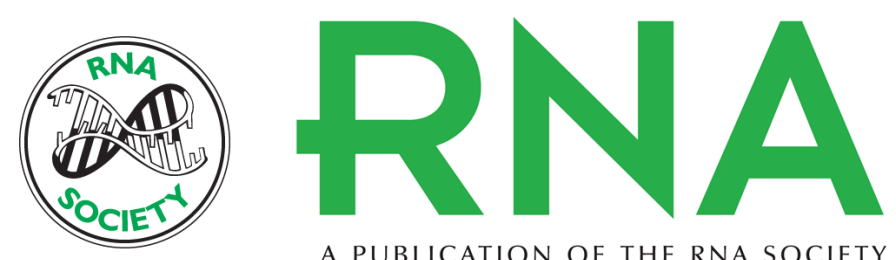

A PUBLICATION OF THE RNA SOCIETY

\section{TRAP-5' stem-loop interaction increases the efficiency of transcription termination in the Bacillus subtilis trpEDCFBA operon leader region}

Adam P. McGraw, Philip C. Bevilacqua and Paul Babitzke

RNA 2007 13: 2020-2033 originally published online September 19, 2007

Access the most recent version at doi:10.1261/rna.719507

References This article cites 59 articles, 30 of which can be accessed free at:

http://rnajournal.cshlp.org/content/13/11/2020.full.html\#ref-list-1

License

Email Alerting Receive free email alerts when new articles cite this article - sign up in the box at the Service top right corner of the article or click here.

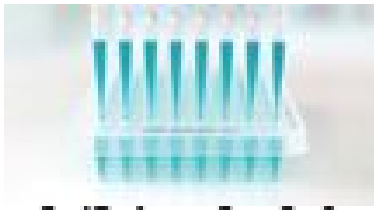

Providing Precise Solutions for your research.

To subscribe to RNA go to:

http://rnajournal.cshlp.org/subscriptions 